\title{
Pacificação e expropriação no Jogo Olímpico
}

\section{Pacification and dispossession in olympic game}

Tamara Tania Cohen Egler - Doutora em sociologia pela Universidade de São Paulo, Professora da Universidade Federal do Rio de Janeiro/UFRJ, atuando no Instituto de Pesquisa e Planejamento Urbano e Regional/IPPUR, no Programa de Pós-Graduação em Planejamento Urbano e Regional. E-mail: tamaraegler@gmail.com

\section{Resumo}

O artigo está associado ao importante papel das redes na atualidade. Nelas podemos observar diferentes modalidades de comunicação, mediadas por tecnologias que transformam as estratégias econômicas e políticas. $\mathrm{O}$ presente texto remete às redes sociotécnicas que associam corporações internacionais, agências internacionais, governos locais e empresas capitalistas, cujo objeto de ação compartilhado é realizar os Jogos Olímpicos na cidade do Rio de Janeiro. O nosso objetivo é revelar como se realiza essa associação de atores, em nível global, e como os interesses privados acabam prevalecendo na formulação de políticas urbanas locais. O artigo busca expor como essas redes sociotécnicas se formam e como atuam na formulação de diferentes processos e quais são os resultados de sua ação. Esses resultados são expressos nos ganhos extraordinários que produzem transformações na vida cotidiana dos habitantes da cidade do Rio de Janeiro, que, elevada à condição de sede dos Jogos Olímpicos de 2016, consolida sua posição no ranking das cidades globais.

\section{Palavras-chave}

Rede sociotécnica. Pacificação. Expropriação.

\begin{abstract}
The article is associated with the important role of networks today. We can observe in these different forms of communication, mediated by technologies that transform the economic and political strategies. This article refers to the sociotechnical networks involving transnational corporations, international agencies, local governments and capitalist enterprises, whose objective is the realization of the Olympic Games in the city of Rio de Janeiro. Our goal is to reveal how this association between actors is globally realized, and how private interests prevail in the formulation of local urban policies. The article seeks to expose how these socio-technical networks are formed and how they act in the formulation of different processes and what are the results of their action. These results are expressed in the extraordinary gains that produce transformations in the daily life of the inhabitants of the city of Rio de Janeiro, as hosting the Olympic Games, consolidates its position in the ranking of global cities.
\end{abstract}

\section{Keywords}

Socio-technical networks. Pacification. Dispossession. 


\section{INTRODUÇÃO}

Para dar início à análise proposta neste artigo, é importante observar os efeitos da globalização sobre o processo espacial. Neles percebemos que as tecnologias de informação e comunicação (TICS) transformam o meio técnico cientifico informacional, ampliam as possibilidades de conexão entre diferentes territórios e definem um novo espaço que podemos denominar espaço global. Percebemos o espaço como fragmentos que se conectam por fluxos de comunicação digital. Essa nova complexidade espacial articula formas materiais e imateriais, agentes públicos e privados, em processos que, atuando de forma rizomática pela mediação tecnológica e pela interação social, transformam as práticas econômicas, políticas e sociais. Sua representação está expressa na conexão entre espaços locais - fragmentos urbanos - e processos comunicacionais - fluxos digitais -, que, articulados, dão origem a um novo espaço que liga o global ao local, constituindo uma totalidade espacial mais complexa e definindo novas formas de delimitação de territórios globalizados (EGLER, 2005).

Os Jogos Olímpicos, por mobilizarem um grande número de agentes, associados na transversalidade das esferas, unificam, numa mesma totalidade, organizações internacionais, como os Comitês Olímpicos, por exemplo, o COI e o $\mathrm{COB}$, capitais que atuam globalmente, como redes de hotéis, agências de turismo e companhias aéreas. Ao mesmo tempo, oferecem vantagens aos governantes locais e a capitais nacionais, que passam a participar da rede, como empreendedores imobiliários, empresas de construção civil e até mesmo organizações sociais, que se associam a essa rede para participar da grande festa global.

Essa política vem sendo implementada, numa escala crescente, em diferentes cidades do mundo, desde a realização das Olimpíadas em Barcelona (1992), passando por Atlanta (1996), Atenas (2004), Pequim (2008), Londres (2012) e Rio de Janeiro (2016). Os resultados da pesquisa são surpreendentes porque revelam a estratégia política que combina, numa mesma totalidade, as dimensões econômica, política e cultural do processo espacial. Vejamos como isso acontece. 


\section{REDES, CIDADES GLOBAIS E LIMITES ENTRE OS PROCESSOS MATERIAIS, IMATERIAIS E SIMBÓLICOS COMO OBJETO DA INVESTIGAÇÃO}

Quando o prefeito César Maia propôs a primeira candidatura do Rio de Janeiro para as Olimpíadas, em 1992, fui assistir ao seu lançamento na praia de Copacabana. Durante a cerimônia, que contou com ampla participação popular, caminhões distribuíam balões de gás ao longo da orla. As filas formadas nas proximidades dos caminhões e compostas por muitas crianças avançavam lentamente. Ao meio-dia, os balões foram soltos e tomaram o céu de Copacabana. Eu pensei: "Esta será a imagem-síntese da solidariedade carioca para a realização dos Jogos Olímpicos". Foi essa a leitura possível da primeira imagem do Rio para os Jogos Olímpicos. À noite, as emissoras de televisão brasileiras transmitiram para o mundo a imagem de uma solidariedade que não tinha referente na vida cotidiana. Por outras palavras, o discurso manifesto pela imagem não corresponde a uma realidade da existência, apenas simboliza uma relação que não existe.

Foi esse fato que originou a nossa pesquisa, tendo como eixo de investigação a observação dos limites entre os processos materiais, imateriais e simbólicos que plasmam a política urbana na atualidade globalizada ${ }^{1}$.

Para participar da rede de cidades globais, o governo do Rio de Janeiro passou a implementar políticas urbanas destinadas a colocar a cidade na competitividade do sistema global. Constituiu-se uma rede de corporações dedicada à promoção de grandes eventos envolvendo a produção de atividades imateriais de forte conotação simbólica, das quais os jogos esportivos, o turismo e os grandes projetos representam apenas a ponta do iceberg. As cidades ocupam lugar de destaque no processo de globalização. Nelas se produzem outras necessidades, que conduzem a novas subjetividades, as quais, por sua vez, redefinem as relações sociais, os corpos e as mentes. Nossa proposta analítica, com efeito, caminha nessa direção, buscando compreender as determinações simbólicas, de natureza imaterial, presentes no contexto de uma sociedade globalizada. Procuramos, assim, fugir de uma abordagem meramente econômica, dedicada a analisar as formas particulares da produção de mercadorias.

\footnotetext{
Examinamos, ao longo dos anos, as políticas urbanas no contexto da globalização (EGLER, 2005a ) e da cidade do Rio de Janeiro, desde a tentativa de revitalização da Zona Portuária (EGLER, 2005b), no primeiro governo de César Maia à frente da Prefeitura da cidade, passando pelos Jogos Pan-Americanos (EGLER, 2007 e 2010), realizados no seu segundo governo, até os dias atuais, quando o governo Eduardo Paes prepara a cidade para a Copa do Mundo e as Olimpíadas.
} 
O objetivo da pesquisa é desvendar os reais interesses que estão associados ao projeto de transformar o Rio de Janeiro na sede dos Jogos Olímpicos, em 2016. Daí a nossa responsabilidade intelectual e cidadã para revelar o que há de essencial no jogo do poder no Rio de Janeiro.

Para fazer a delimitação do objeto, foi necessário conhecer o megaprojeto em execução na cidade que inclui a instalação de Unidades de Polícia Pacificadora (UPPs), a remoção de populações, a construção de equipamentos para jogos esportivos, a produção de fluxos de transporte e de informação por comunicação digital. O objetivo da pesquisa foi, pois, desenhar os contornos da ação que move a totalidade dos interesses que estão implícitos nessa estratégia de ação política.

Esse é o ponto de inflexão que possibilitou o avanço de nossa pesquisa sobre a natureza do processo espacial, ajudando-nos a perceber que, além de sua forma material e tangível, os processos de apropriação social são imateriais e intangíveis.

Para tanto, delimitamos os seguintes objetivos:

- desvendar o discurso oficial;

- identificar a rede de atores associados ao megaprojeto de realização dos Jogos Olímpicos na cidade;

- mapear os equipamentos destinados à realização dos jogos esportivos;

- investigar a implementação das UPPs e analisar o processo de pacificação e expropriação para tornar claros os interesses em jogo;

As perguntas podem, então, ser assim enunciadas:

- como é o discurso oficial?

- quais são os atores que formam a rede de territórios da globalização, como eles se associam e quais são seus interesses?

- como se realiza o processo de pacificação?

- qual é o plano urbano dos Jogos Olímpicos?

- como se realiza a expropriação?

O debate está aberto e a questão teórica está colocada para aqueles que acreditam que o capitalismo se perpetua, transvertido, e aqueles que examinam as transformações na ordem dos fatos, atores e processos que estão delineando uma nova complexidade. Concretizada no entrelaçamento da investigação econômica, política e cultural no espaço, essa complexidade de novo tipo exige uma orientação analítica alternativa, capaz de permitir um avanço na compreensão da realidade vivida. 
Nossa pesquisa revela as formas complexas de articulação entre as redes de atores globais, dedicados à produção simbólica dos Jogos Olímpicos, e os processos de expropriação social. Se, no capitalismo industrial, a política urbana produz mercadorias de natureza física e tangível, na globalização a materialidade desaparece para dar lugar ao desenvolvimento de atividades imateriais, de natureza simbólica.

O significado de rede vem exigindo definições precisas, o conceito está permeando o tecido social, todo mundo fala em redes sociais. Nós queremos precisar como as redes são formadas por uma dimensão social técnica e outra técnica (EGLER, 2007), quer dizer elas são de natureza sociotécnica. Ao mesmo tempo lembramos que as redes sempre existiram, Norbert Elias (1994) já se refere a elas desde 1939, a sociedade sempre se organizou em grupos que tem objetivos compartilhados. Por exemplo, sindicados, partidos políticos, movimentos sociais. $\mathrm{Na}$ atualidade, o que se transforma é o meio técnico que permite maior conectividade e comunicabilidade, amplia as possibilidades de ação coletiva. No presente artigo, estamos observando as redes que se formam na transversalidade e associam corporações, organizações e capitais internacionais e nacionais e governos locais para o objetivo compartilhado de realizar os jogos olímpicos e os lucros extraordinários. Portanto, o objetivo do artigo é desvelar a estratégia de pacificação e expropriação que move os interesses da rede global.

Estamos, portanto, diante de dois processos: o primeiro, que associa atores globais em rede; e o segundo, que produz rede de territórios globalizados. $\mathrm{Na}$ realidade, estamos diante de um processo de destruição/construção do espaço urbano carioca, cujo objetivo é prepará-lo para servir de cenário à realização da Copa do Mundo (2014) e dos Jogos Olímpicos (2016), destinando-o às atividades econômicas imateriais de natureza simbólica. Em outras palavras, a política urbana foi reduzida aos interesses da rede global, cujo objeto de ação é a produção de uma rede de territórios resultante do processo de apropriação social do uso do solo urbano, restrito às elites globais.

Cabe, aqui, estabelecer uma distinção conceitual entre espaço, cidade e territórios, que nos ajude a esclarecer o que queremos dizer com rede de territórios. O espaço é uma categoria abstrata que pode estar referida à compreensão do que se considera ação social, técnica e objetos materiais, para dialogar com Milton Santos (1994, 1998) e Ana Clara Torres Ribeiro (2010, 2011). Cidade - tanto o Rio de Janeiro, quanto Tóquio ou Catanduva - é a condensação de processo espacial em formas materiais historicamente determinadas. Para compreender o conceito de território, devemos recorrer a Cláudio Egler (2005) e Marcelo Souza (2007), que revelam a dimensão política do espaço. Estamos falando do 
exercício do poder sobre um fragmento do espaço geográfico ou arquitetônico, que pode ser tanto o quarto do casal dentro do apartamento, uma fazenda, uma rua, quanto um equipamento para atividades esportivas. Daí a referência que entende a rede de territórios como fragmentos que se conectam por fluxos de comunicação e formam uma rede de territórios locais, os quais, por sua vez, se conectam por fluxos comunicacionais e formam um espaço global (EGLER, 2005). Desse modo, pretendemos apresentar evidências empíricas e, a seguir, proceder a uma análise que dê conta da complexidade do negócio dos grandes eventos esportivos.

Para participar da rede de cidades globais, o governo do Rio de Janeiro passou a implementar políticas urbanas capazes de colocar a cidade na competitividade do sistema global. Observamos, assim, a formação de uma rede de corporações dedicadas à produção de um cenário urbano para abrigar jogos esportivos, desenvolver o turismo e realizar lucros extraordinários. Essa mega operação, que está associada a uma estratégia própria de ganhos econômicos, difere profundamente da produção de mercadorias na fábrica. Nela os conceitos de mais-valia, lucro e renda são insuficientes para dar conta da complexidade do negócio que está acontecendo. Primeiro, porque o processo de acumulação difere da produção de mercadoria clássica; segundo, porque o objeto de apropriação de capital-dinheiro é imaterial e está referida aos sentimentos nacionais que resultam da disputa esportiva. Ao vender os jogos esportivos, vende-se, ao mesmo tempo, a imagem da cidade que vai ser vista por milhões de telespectadores.

Nosso desafio é fazer a demonstração dessa hipótese que considera perversa a apropriação de sentidos e sentimentos socialmente produzidos em capital-dinheiro pelos atores que participam da rede. Na realidade, a mercadoria não é a cidade. Ela está referida aos sentimentos das pessoas, sendo, pois, de natureza simbólica. Afinal, a mais-valia não resulta da expropriação da força de trabalho, mas da manipulação de sentimentos humanos em prol da realização de lucros extraordinários.

Essa gigantesca operação voltada para a realização da também gigantesca reforma urbana exige um enorme investimento na produção dos equipamentos necessários para a realização do evento. Isso determina a elevação do preço da terra e a realização de lucros extraordinários em forma de renda da terra. Não se trata, portanto, de expropriação da força de trabalho, mas de realização de rendimentos fundiários. Por isso, não é possível compreender a cidade como mercadoria. Marx (1978), no livro III do Capital, já nos alertava para o fato de que a terra não tem valor, tem preço. O que acontece na cidade do Rio de Janeiro é uma valorização do capital imobiliário, determinada pelo incremento dos 
investimentos que potencializa a elevação do preço e da renda da terra (EGLER, 1986). Trata-se de um megaprojeto de acumulação de capital que associa um sem-número de atores, dedicados à produção de uma economia associada à realização de capital simbólico e distinção social.

\section{QUAL É O DISCURSO OFICIAL?}

O discurso oficial confere primazia ao desenvolvimento da economia. A argumentação está associada à capacidade de impactar a economia, ampliar a capacidade de acumulação e promover o aumento do número de empregos. Esses fatores gerariam impactos positivos no turismo, mediante a divulgação, nacional e internacional, da marca Rio de Janeiro, na arrecadação municipal e, por derivação, no desenvolvimento social.

Por ocasião dos Jogos Pan-Americanos (2007), a Prefeitura despendeu em torno de $\mathrm{R} \$ 3,5$ bilhões, e a atividade econômica decorrente desses gastos gerou $\mathrm{R}$ \$ 6,7 bilhões $^{2}$. Em outras palavras, o governo da cidade investe na produção de territórios para equipamentos esportivos e outros empreendimentos e a iniciativa privada realiza duas vezes mais o investimento feito. Estamos diante de uma estratégia inovadora de expropriação, uma vez que todos os moradores da cidade pagam a construção dos equipamentos esportivos e a iniciativa privada se beneficia com a acumulação que resulta das atividades de turismo. O que nos parece mais grave é o enorme investimento público em atividades privadas de natureza efêmera. Quando a festa acaba, os turistas vão embora, as construções são removidas, os empregos desaparecem e pouco do que foi o megaevento resta para a cidade e seus habitantes.

Quando examinamos os dados do turismo, tudo fica mais claro. De acordo com o estudo Impactos socioeconômicos dos Jogos Pan-Americanos Rio-2007, da Fundação Instituto de Pesquisa Econômica (FIPE), 91,7\% das pessoas que acompanharam os Jogos Pan-Americanos eram residentes no Brasil. Os demais 8,3\% vieram de outros países. Isso pode significar que o Rio talvez não seja, por assim dizer, um polo turístico internacional. $\mathrm{Na}$ realidade os turistas eram, sobretudo, brasileiros, e, assim, não foram tantos os dólares injetados na economia carioca.

Se olharmos mais de perto a pesquisa da Fundação Getúlio Vargas (2008), verificamos que o setor de turismo realizou parcos $\mathrm{R} \$ 118$ milhões, os restaurantes e hotéis apresentaram um aumento de $18 \%$ das atividades na região da Barra da Tijuca, e, na Zona Sul, o crescimento foi de 7\% nas atividades dos

2 Jornal do Brasil, Fabio Grijó, "Pan-2007 movimentou R\$ 10 bilhões”, 29/09/2009. 
restaurantes e 10\% nas dos bares. A média de ocupação dos hotéis em julho de 2007, o mês do Pan, foi de 66,07\% contra 56,66\% da média do mesmo período em 2006. Isso significa que o crescimento não teve nada de extraordinário, se considerarmos o custo social do investimento realizado na produção do cenário para os jogos esportivos.

\section{REDE GLOBAL PARA MEGAEVENTO LOCAL}

Que atores formam a rede global das cidades? Como eles se associam? Quais são seus interesses?

Se partirmos de um ponto de vista que valoriza a rede de atores globais, podemos começar dizendo que, ao dissecar as partes para entender o todo, é preciso descobrir o interior das redes globais, que se apresentam de forma invisível e altamente complexa. Elas têm peso e leis próprias, constituem-se como unidades menores a compor as maiores por meio de suas inter-relações. O desafio é entender tais relações que comportam estruturas e regularidades próprias, que fazem a liga entre as suas partes e que moldam e remodelam as redes capazes de fazer a coesão desses atores em benefício de objetivos particulares e compartilhados. Se a identificação dos atores é muito importante, não menos o são os objetivos em prol dos quais atuam. Mas é preciso observar o conjunto de estratégias que amplia a mobilidade de pessoas em torno de cidades globais e em busca da satisfação de um desejo de consumo de bens imateriais, associado ao entretenimento e à satisfação simbólica.

A sociedade de consumo de bens duráveis está esgotada. Vivemos em uma sociedade que consome bens não duráveis e intangíveis. Daí a importância do turismo internacional, que estimula a mobilidade das pessoas ao redor do mundo e produz ganhos econômicos extraordinários. Para alavancar essa mobilidade, costuma-se realizar grandes eventos - na área dos esportes, da cultura, da música, dos festivais de cinema, dos congressos científicos - que sejam capazes de concretizar a estrutura móvel da globalização. Pouco resta dos primórdios da fábrica e da vila operária; estamos diante de uma poderosíssima organização em redes sociotécnicas, que promove atividades que têm como palco as cidades e que se associam em redes globais.

O processo de globalização tem outra forma específica de organização do poder. A rede global agrega atores econômicos, políticos e sociais de diferentes países do mundo. Não se identifica o seu comando; incorpora todos os atores 
dentro de uma ação que se expande rizomaticamente (EGLER, 2009). É muito difícil identificar toda a ampla gama de atores associados à rede dos megaeventos, que inclui um grande número de atores, desde as organizações esportivas internacionais - como a FIFA e os Comitês Olímpicos - as cadeias de hotéis, os atores governamentais, capitais nacionais e internacionais dedicados a um semnúmero de atividades, até as organizações sociais.

Por ocasião da segunda - e vitoriosa - candidatura do Rio à sede dos Jogos Olímpicos, em Copenhague, em 2009, foi possível começar esse trabalho de identificação de seus principais atores. Podemos nomear os principais dirigentes da FIFA, do Comitê Olímpico Internacional, do Comitê Olímpico Brasileiro, do governo local. O discurso dos atores na defesa do Rio para sediar os jogos Olímpicos é conhecido, enaltece o desenvolvimento econômico e enobrece os jogos por criar um sentido de união dos povos. ${ }^{3}$ Não há como negar que a Rede Globo é um dos parceiros principais entre os atores que participam da rede do jogo. Uma simples leitura de jornais nos permite perceber como se produz um discurso favorável aos interesses daqueles agentes.

Olivro de Andrew Jennings, Jogosujo (2011), éclaro quando revela os bastidores da FIFA e os ganhos auferidos por ela com a realização da competição nos países do futebol. Sabemos que a FIFA é dona de uma empresa de telecomunicação que se responsabiliza pela difusão dos jogos, em todo o mundo. Podemos imaginar os lucros alcançados com essa megaempresa de telecomunicação, que cobra milhões de dólares para veicular propaganda no sentido de ampliar o consumo de uma ampla variedade de mercadorias em escala mundial. O negócio é vender a competição, ganhar com a publicidade e a venda dos ingressos. A cidade se transforma em cenário privilegiado para a realização de um espetáculo global, que vai difundir os jogos da Copa do Mundo e das Olimpíadas para todo o planeta. Os resultados dessa pesquisa nos permitem imaginar o conjunto de atores que se beneficia desse processo, estando a FIFA em primeiro lugar.

Nessa estratégia do processo de globalização, são produzidas outras necessidades que conduzem a novas subjetividades, as quais redefinem as relações sociais, os corpos e as mentes. Com isso, evitamos uma abordagem meramente econômica, que subordina ao capital dinheiro o capital político e o social. Partindo dessa premissa, nos foi possível estabelecer, de uma forma geral, a seguinte pergunta:

Como é o plano urbano para os grandes eventos?

Rio 2016 aposta em "legado real” e maciço apoio popular. Em 02/10/2009http://esportes. terra.com.br/interna/0,,OI4016520-EI1894,00-io +aposta + em + legado + real + e+macico + apo io+popular.html. 
Antes de responder à pergunta, é importante destacar que o governo da cidade não apresenta o megaplano para os eventos - dispomos apenas de "pedaços" de plano. O objetivo aqui é fazer a articulação entre as UPPs, equipamentos esportivos, Vila Olímpica e transportes. Trata-se de montar um quebra-cabeça, para encontrar os fios condutores que revelam a complexidade da política e do projeto urbano que movem o interesse dos agentes que participam da realização dos megaeventos. É muito triste, por que se trata de recursos públicos, originários do trabalho de todos, que estão sendo dilapidados em troca de nada.

Para responder a essa questão, identificamos dois eixos de ação: • pacificação de territórios • cenarização do espaço urbano.

\section{PACIFICAÇÃO DE TERRITÓRIOS}

A política de pacificação da cidade do Rio de Janeiro está constituída a partir de um conjunto de ações que tem por objetivo transformar as relações entre a polícia e a comunidade, visando, com isso, levar a paz aos bairros populares. Trata-se de uma forma de pensar que valoriza a comunicação entre os moradores e os integrantes das forças policiais. A enunciação do discurso se define pela substituição de uma ação de repressão por uma de participação. Essa política foi inspirada numa estratégia do governo colombiano contra o tráfico de drogas e o aumento da violência urbana. É conhecida a condição da violência da cidade de Medellín, e a política do governo colombiano de combate à violência foi transferida para o Brasil e para outros países da América Latina.

Conhecemos bem a história da violência no Rio de Janeiro, que vem desde que o tráfico tomou conta dos bairros populares e trouxe, para a vida cotidiana, a luta armada entre facções, o assassinato de crianças, jovens e adultos, e efeitos perversos sobre a vida familiar dos usuários de drogas. Para avançar nessa análise, é importante tornar claras as condições da violência na cidade. O mapa I apresenta a localização das UPPs no espaço urbano carioca vis a vis a existência de favelas, é um bom ponto de partida.

Podemos perceber a olho nu o que acontece na cidade. Os pontos vermelhos identificam as mais de 600 favelas e os azuis designam as áreas onde ocorre a intervenção das UPPs. A análise de Alice Ribeiro revela como sua localização está organizada em torno dos equipamentos que serão construídos para a realização dos jogos (RIBEIRO, 2011). Para nós, importa perceber de que forma a pacificação se realiza na cidade e quais são os resultados alcançados 
com essa política. Como podemos observar, as UPPs estão localizadas, em sua grande maioria, na Zona Sul, certo número na Zona Norte e poucas na Zona Oeste. A escolha está mais associada ao preço da terra na localidade do que necessariamente ao processo de pacificação.

Mapa 1 - Localização de Favelas e UPPs e Equipamentos Olímpicos no Rio de Janeiro, 2011

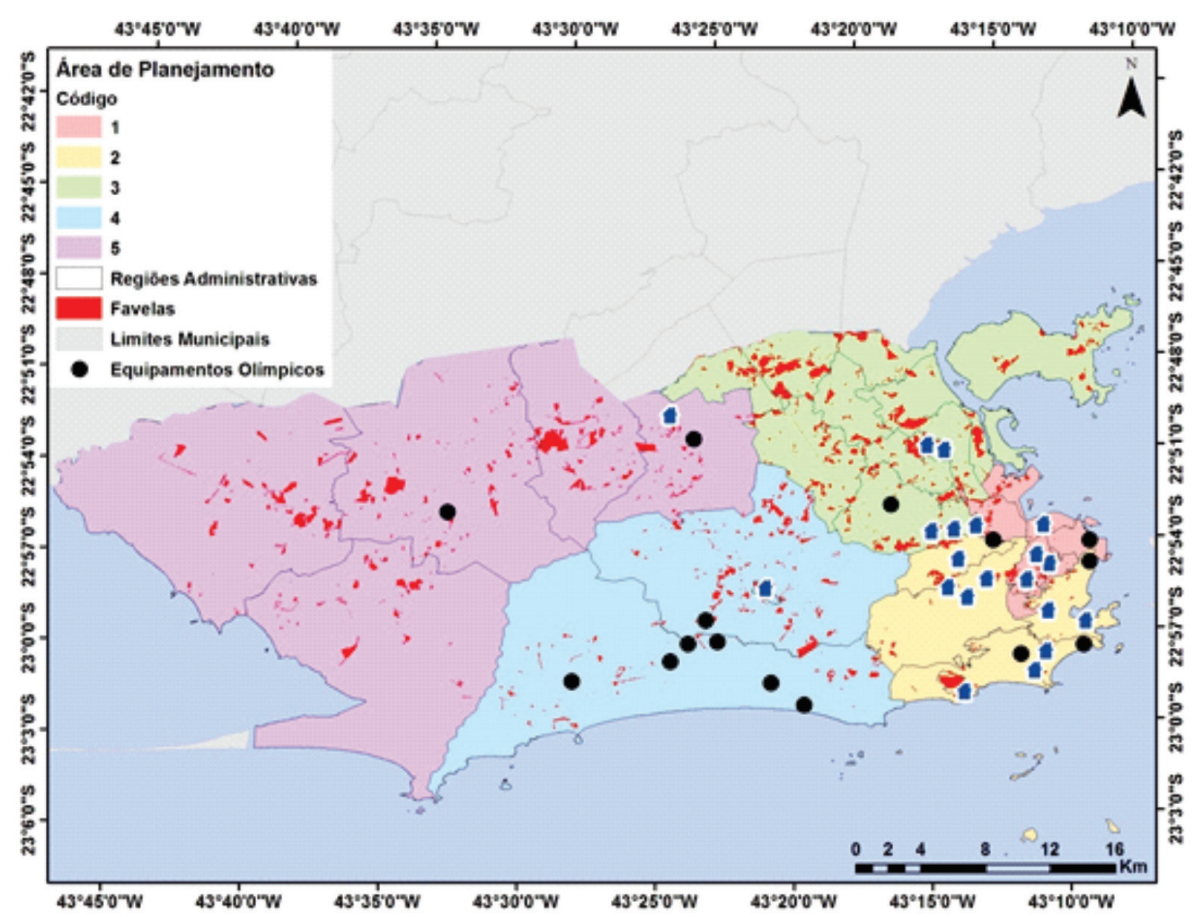

Fonte: Levantamento realizado por Alice Ribeiro e Felipe Fernandes, bolsistas de IC, e mapa feito por Ricardo Sierpe.

$\mathrm{Na}$ realidade, as UPPs controlam a violência dentro dos territórios pacificados, mas o que podemos observar é que as milícias e o tráfico de drogas estão deslocando suas atividades e levando a violência para outros lugares. Isso explica a ampliação do número de roubos, furtos e assassinatos, em outras periferias da cidade. Em outras palavras, existe uma pacificação dos territórios onde as UPPs estão presentes, mas o terror se espalha em territórios pobres, não globalizados. Alba Zaluar (2005) revela como os pobres são as maiores vítimas de furtos, roubos e assassinatos, estes últimos nos locais onde o tráfico de drogas domina e não há policiamento que proteja a população. 
Sabemos que as favelas são dominadas pela força instrumental das milícias, que escraviza moradores e comerciantes. A análise dos dados sobre os resultados alcançados com a ação das UPPs permite perceber que nas áreas em que elas atuam houve, efetivamente, uma queda no número de homicídios no primeiro semestre de 2012, em comparação com todo o ano de $2011^{4}$.

Para entender essa violência, é necessário conhecer as origens da constituição do mercado de drogas. Sabemos que a informalidade e a tolerância com traficantes permitiram a emergência e a consolidação de um mercado de drogas altamente organizado. Essa política nos permite compreender como se deu o domínio dos traficantes armados sobre seus territórios a partir dos anos 1970, com a proteção promovida por governos em todas as suas escalas: local, regional e nacional.

Não menos importante é o número de pessoas que trabalham no tráfico, principalmente de menores. Estimativas de 2007 revelam que nesse ano $\underline{15.658}$ menores de 18 anos exerciam atividades remuneradas para traficantes da capital e da Baixada Fluminense. Apesar da queda, o contingente de meninos envolvidos hoje com o tráfico ainda é alto, cerca de 10 mil..$^{5}$ Sua importância na economia do Rio pode ser lida no aquecimento da economia das favelas, porque gera emprego, permite a lavagem de dinheiro e movimenta o capital imobiliário nas favelas. Com certeza, o saldo é negativo, se considerarmos os seus custos sociais.

De fato, as estatísticas revelam uma redução de $24,2 \%$ no número de vítimas de homicídio doloso, de $32 \%$ nos homicídios provocados por arma de fogo e de 48,1\% nas mortes com tipificação provisória. ${ }^{6}$ Registrou-se também uma diminuição de $22,7 \%$ dos roubos de carga e de $27,7 \%$ de veículos. Ao mesmo tempo em que diminuem os homicídios, as estatísticas indicam um expressivo aumento no número de roubos a transeuntes (229,6\%). Também os casos de furto apresentaram expressivo aumento $(97,8 \%)$. Houve um incremento de $55,9 \%$ no total de registros identificados no estado (RIBEIRO, 2011), o que nos permite depreender que a violência passou da droga para o roubo dos pobres. Mudaram apenas os atores e os objetos de ação. No lugar do tráfico de drogas, roubam-se celulares e os salários dos pobres.

4 Áreas de UPP registram 6 homicídios no 1. o semestre de 2011, diz ISP. Disponível em: http:/ / g1.globo.com/rio-de-janeiro/noticia/2011/09/areas-de-upp-registram-6-homicidios-no-1semestre-de-2011-diz-isp.html - Atualizado em 14/09/2011 15h39.

5 UPPs R7 - 04/07/2011). Disponível em: http://noticias.r7.com/rio-de-janeiro/noticias/ upps-afastam-mais-de-3-600-menores-de-idade-do-trafico-no-rio-diz-instituto-20110704.html

6 "O segmento 'Vítimas de mortes com tipificação provisória' refere-se às ocorrências nas quais não foi possível caracterizar, no momento do registro, a causa da morte como natural ou externa. Nesses casos, dois tipos foram considerados: encontro de cadáver e encontro de ossada" (ISP, p. 6). Diponível em: http://www.dadoslivres.com/crimes-no-estado-do-rio-dejaneiro/vitimas-de-morte-com-tipificacao-provisoria/ visualizado em 05/08/2012

Novos Cadernos NAEA • v. 18 n. $1 \bullet$ p. 197-214 • jan-jun. 2015 
O problema da violência não é um problema de polícia. É um processo histórico, que permitiu a consolidação da pobreza, do desemprego e da perversa exclusão dos mais pobres do seu direito a condições dignas de vida. Além disso, os órgãos de governo fizeram a defesa de interesses econômicos e políticos associados às redes de produção e comercialização de drogas. Trata-se de um problema social que exige políticas sociais de desenvolvimento, nas áreas de educação, saúde, habitação, transportes e justiça.

\section{EXPROPRIAÇÃO DO DIREITO À CIDADE}

Para avançar na nossa demonstração, é preciso compreender a expropriação que está associada à pacificação. Para isso, vale a pena conhecer um pouco da história da luta pelo espaço que deu origem às favelas, no Rio de Janeiro. Elas se localizam, principalmente, nos morros da cidade, onde é proibida a construção da habitação formal, a partir de um processo de autoconstrução em tijolo, madeira e telha. Seu resultado é conhecido: uma paisagem da pobreza tanto no que se refere ao saber técnico, quanto às condições econômicas. Nesse espaço, onde transcorre a vida cotidiana, encontramos relações sociais de confiança, solidariedade e natalidade, e também de violência, destruição e mortalidade.

Os mais ricos celebram sua existência no jogo da vida urbana, quando se representa a riqueza e a pobreza pelas condições de moradia. Com certeza, a casa é o passaporte simbólico mais importante do sujeito no campo social, pois revela o capital dinheiro e o capital social que o seu detentor possui. Assim, os mais ricos se dignificam pela propriedade da casa e por sua localização. Por isso, ao longo da história do Rio de Janeiro, a favela sempre foi objeto da cobiça dos mais ricos sobre os mais pobres. Conhecemos as especificidades do processo de favelização no Rio de Janeiro. Enquanto em São Paulo, por exemplo, a localização dos pobres acontece na periferia, no Rio de Janeiro a encontramos também nas zonas nobres. Basta pensar na Rocinha ao lado de São Conrado ou no Santa Marta, em Botafogo.

A história da habitação no Rio de Janeiro é marcada pela forte resistência social dos pobres que habitam a cidade. Ao longo do tempo, é possível identificar a emergência de movimentos sociais altamente organizados para colocar limites aos interesses manifestos do governo da cidade associado ao capital imobiliário nacional. A existência de pobres no Rio resulta de uma luta política para criar condições de acesso à infraestrutura urbana e a serviços de educação, saúde e de regularização fundiária. Toda essa história leva o nosso pensamento para a atualidade do acontecer. 
Uma vez que não foi possível erradicar as favelas - e que também não foi possível removê-las nem urbanizá-las -, a política para as favelas se transforma profundamente. O que se propõe é, simplesmente, transferir moradores de classe média e alta, e também turista, para o lugar dos pobres. Através de um processo de pacificação e ordenação, inverte-se a política, criando-se condições para a subida dos ricos para os territórios pacificados. Quer dizer que as favelas, ao lado dos equipamentos, fazem parte do mapa que representa a rede de territórios globais.

No Rio de Janeiro, temos assistido a um processo em que a vida cotidiana nas favelas tem sido apropriada pelos turistas como objeto de contemplação. Estamos nos referindo aos tours que levam os turistas para conhecer o "lado belo" da vida nas favelas. Quando vejo as peruas circulando pelas ruas da cidade, cheias de turistas com chapéus na cabeça, lembro-me das caçadas nas savanas da África. É triste ver como as condições de vida cotidiana nas favelas cariocas são transformadas em objeto de consumo contemplativo. Turistas de todas as origens - europeus, americanos e orientais - fazem desse passeio uma forma de apropriação da cultura social do nosso modo de sentir e viver. Parece que fomos transformados em animais que se relacionam de forma espontânea e natural, capazes de sorrir e cantar. Nessa equação, a vida se transforma em objeto de consumo e a favela em objeto do desejo.

O modo de vida nos países do Primeiro Mundo está em crise; as relações humanas, empobrecidas. Para fazer avançar o processo de expropriação nada melhor do que vender uma cidade onde se canta, se dança e se ama. Como não há espaço para todos, então, mais uma vez, os mais pobres são expropriados para dar lugar aos mais bem situados na hierarquia social, e assim ampliar as condições de ganho para o capital dedicado à atividade imobiliária.

Nessa perspectiva, morar na favela é viver bem. Lá as pessoas se comunicam, brincam umas com as outras, fazem música, dançam e promovem festas. A favela se torna lúdica e vende-se a ilusão de uma vida cotidiana em comunidade. Pouco a pouco, ela se transforma. Surgem projetos governamentais como o Programa de Aceleração do Crescimento (PAC), casas são pintadas com muitas cores, prédios de apartamentos são construídos, são implementados serviços públicos e privados nas favelas, que se localizam principalmente em áreas nobres da cidade.

O discurso do atual prefeito carioca, Eduardo Paes, sobre a favela mostra grave distorções. Para ele, a pobreza é produto da desordem e, por isso, a ordem urbana é celebrada pelo ocultamento dos pobres. Estamos diante de uma atividade econômica de natureza simbólica, que tem por objetivo a reforma da 
cidade na produção de uma espacialidade que valoriza os modelos hegemônicos do urbanismo (RIBEIRO, 2004). É um programa de ação perverso, que bane do espaço urbano o trabalho biscateiro (RIBEIRO, 1977) e a habitação social. Fica tudo homogeneizado e uniformizado, perde a alegria e a criatividade da existência social na cidade.

A proposta urbanística é produzir uma ordem material, associada a um gosto homogeneizado, que responde por uma cultura alheia ao gosto e às formas de ser, sentir, comercializar e viver das classes populares no Rio de Janeiro. Limpar significa controlar, impedir, imobilizar, proibir, a vida na cidade. Ao tirar as pessoas, tira a vida do lugar. Essa ação se estende por vários lugares e setores da economia informal. Na orla, no centro, nos estádios, nas ruas da Zona Sul, a ação do policiamento responde por uma mesma lógica de expropriação.

O plano de remoção de favelas na cidade tem um novo nome. No lugar do programa Favela-Bairro, ${ }^{7}$ o prefeito Eduardo Paes lança o Morar Carioca, um ambicioso plano que pretende se tornar, pelos próximos dez anos, a política pública de referência para a urbanização de todas as favelas da cidade. O novo programa tem por objetivo transformar as favelas em bairros formais elegalizados, controlar a construção da paisagem mediante um código de obras, com gabarito e afastamentos demarcados, além de implantar, nessas comunidades, a política do “choque de ordem" em caráter permanente. Haverá uma secretaria especializada na manutenção dos equipamentos públicos e na conservação do espaço urbano. As favelas que estiverem em áreas de risco e não forem urbanizáveis serão removidas. ${ }^{8}$

O que está em jogo é um processo de expulsão dos pobres da cidade $\left(\right.$ COELHO, 2012) ${ }^{9}$ em benefício da implantação de um megaprojeto urbano para transformá-la em um cenário para a realização de grandes eventos, quer sejam eles esportivos, musicais ou ainda congressos acadêmicos. Para isso, são contraídos empréstimos gigantescos, destinados à construção de equipamentos desnecessários, socialmente inúteis, que em nada contribuem para a melhoria da

\footnotetext{
O programa Favela-Bairro foi implementado na administração do prefeito Cezar Maia, em 1993, quando Sergio Magalhães era secretário de Habitação. Seu objetivo era a integração da favela à cidade, por meio da melhoria das condições de acessibilidade e de infraestrutura, visando assegurar condições de habitabilidade minimamente dignas. Vale lembrar que foi realizado concurso público para identificar as necessidades de cada favela contemplada com o programa.

8 MAGAlHÃES, Luis Ernesto (Globo Online). Prefeitura lança novo plano para favelas, que prevê controle, gabarito, conservação e choque de ordem. 24/07/2010. Disponível em: http:/ / oglobo.globo.com/rio/mat/2010/07/24/prefeitura-lanca-novo-plano-para-favelas-quepreve-controle-gabarito-conservacao-choque-de-ordem-917235441.asp

9 Palestra proferida pelo vereador Eliomar Coelho, por ocasião da realização do seminário Políticas públicas: interações e urbanidades, da RPP do programa Pronex da Faperj, Rio de Janeiro, 2011
} 
vida das pessoas na cidade. O que estamos assistindo é um verdadeiro processo de expropriação das condições de existência social. É uma ordem da materialidade dos objetos, na qual se ignora as necessidades de vida e de trabalho nas ruas da cidade que viabilizam a vida das pessoas. Mais uma vez, estamos diante de uma política na qual em nome da ordem material se nega o direito à vida social.

É uma nova onda de periferização, que se consubstancia tanto na política destinada às favelas, quanto na retirada de populações pobres, no programa Minha Casa Minha Vida, na remoção da Vila Autódromo e na proibição do espaço público para as atividades de comércio dos pobres. As pessoas são aprisionadas em suas casas, o trabalho é proibido e o espaço da cidade é reduzido a periferias longínquas, onde não se criam condições de habitabilidade e de existência social. (CARDOSO e alli, 2011)

Se o Rio de Janeiro ocupa a décima posição no ranking das cidades globais ${ }^{10}$, no que diz respeito aos índices sociais a situação é bem diferente. De acordo com pesquisa da ONU, em 2009 o Brasil ocupava o 75. lugar no que se refere ao IDH. A pesquisa ainda informa que em 2006 o país ocupava o $70 .^{\circ}$ lugar, piorando, portanto, sua posição relativa aos indicadores sociais.

Estamos diante de uma política de expropriação do Estado em relação às classes populares. Ou, em outras palavras, "O Estado trabalha contra as pessoas, em nome do bem"11. A ordem está associada ao encaixotamento da vida, à sua imobilização em bairros periféricos, onde não existem condições de habitabilidade, entendidas como infraestrutura, transportes urbanos, trabalho, escola, saúde, ali onde é necessário recomeçar a construção de um novo bairro para os pobres da cidade. É uma política perversa que coloca a ordem física contra a vida social.

Ordem e desordem se constituem em duas faces da mesma moeda. É uma ideologia fascista que impede a ordem do pobre e aniquila o outro. É como holocausto, que nega o direito à vida para os diferentes, quer sejam judeus, ciganos, deficientes físicos ou gays. Mas, como nos ensina Arendt (1994), não há como impedir o recomeço. Os homens da ordem ou da raça estão fadados ao fracasso, porque a vida não para. Falta-lhes sentido à sua ação, porque esta impõe um significado à ordem que é alheia às condições de existência social no lugar, impõe um gosto que é associado a uma cultura estética uniforme, homogênea, fashion, impõe uma forma de pensar, sentir e representar o mundo e a nossa

10 Conforme pesquisa da RioConvention andVisitors Bureau (RC\&VB), disponível em http:/ / siteoficial.com.br/index2.asp?S=Rio-Convention--Visitors-Bureau---RCVB $\& \mathrm{R}=2014 \& \mathrm{C}=1 \& \mathrm{~L}=18040$

11 Apresentação da professora Ana Clara Torres Ribeiro em exame de qualificação para dissertação de mestrado, de Vinicius Carvalho Lima, Rio de Janeiro, IPPUR/UFRJ, 2011. 
cidade alheia ao lugar. Faz-se uma embalagem da vida a ser adquirida no mercado de bens simbólicos da globalização. A rede sociotécnica, dedicada à realização do projeto urbano para os Jogos Olímpicos, proíbe a existência de pobres na cidade para produzir territórios sem vida.

\section{REFERÊNCIAS}

ARENDT, H. A dignidade da política. Rio de Janeiro: Relume Dumará, 1994. BOURDIEU, P. O poder simbólico. Rio de Janeiro: Bertrand Brasil, 1998.

CARDOSO et al. A produção da moradia popular na Região Metropolitana do Rio de Janeiro (RMRJ): O caso dos Conjuntos Habitacionais do Programa Minha Casa Minha Vida em Realengo. Relatório de pesquisa. Rio de Janeiro: UFRJ, 2011

COELHO, E. Palestra. In: SEMINÁRIO POLÍTICAS PÚBLICAS: INTERAÇÕES E URBANIDADES, 2011. Rio de Janeiro. Palestra... Rio de Janeiro: Pronex; FAPERJ, 2011.

EGLER, C. A. G. Questão regional e gestão do território no Brasil. In: CASTRO, I. E. de; GOMES, P. C. da C.; CORRÊA, R. L. (Orgs.). Geografia: conceitos e temas. Rio de Janeiro: Bertrand Brasil, 2007.

EGLER, T. T. C. Espaço social e politica urbana global. In: Cohen, T. T. E.; POGGIESE, H. (Org.). Otro desarrollo urbano: ciudad incluyente, social y gestion democratica. Buenos Aires: Clacso, 2009. p. 63-77.

EGLER, T. T. C. O chão de nossa casa. A produção da habitação em Recife. 1986. Tese (Doutorado em Sociologia) - Instituto de Filosofia, Letras e Ciências Humanas, Universidade de São, Paulo São Paulo, 1986.

. Políticas urbanas globais para espaços locais. Economia, Sociedade e Território, v. 5, n. 17, jan.-jun. 2005.

Jogos Pan-Americanos para um Rio global. In: VALENÇA, M. Globalização e marginalidade: transformações urbanas. Natal: EDUFRN, 2007.

- Jogo no Rio. Revista Brasileira de Estudos Urbanos e Regionais, v. 12, n. 2, 2010.

ELIAS, N. A sociedade dos indivíduos. Rio de Janeiro: Jorge Zahar, 1994. 
GRIJÓ, F. Pan-2007 movimentou R\$ 10 bilhões. Jornal do Brasil, 29/09/2009 Disponível em: <http://jbonline.terra.com.br/pextra/2009/09/29/e29099368. asp.>. Acesso em: 10 mar. 2014.

JENNINGS, A. Jogo Sujo. São Paulo, Panda Books, 2011.

JOHNSON, S. Emergência. A dinâmica das redes em formigas, cérebros, cidades e software. Rio de Janeiro: Jorge Zahar, 2003.

MARX, K. El capital. Critica de la economia política. v. 3. Cidade do México: Fondo de Cultura Económica, 1978.

RIBEIRO, A. UPP em Santa Teresa. Relatório Técnico de Pesquisa . Rio de Janeiro: Faperj, 2011.

RIBEIRO, A. C. T. Trabalho urbano: biscate e biscateiros. 197. Dissertação (Mestrado) - Instituto Universitário de Pesquisas do Rio de Janeiro, Rio de Janeiro, 1977.

Oriente negado: cultura, mercado e lugar. Cadernos PPG-AU/ FAUFBA, v. II, p. 97-107, 2004.

SANTOS, M. A natureza do espaço: técnica e tempo, razão e emoção. São Paulo: Hucitec, 1996.

SANTOS, M. Técnica, espaço, tempo. São Paulo: Hucitec, 1994.

SANTOS, M. Por uma outra globalização - do pensamento único à consciência universal. São Paulo: Record, 2000.

SOUZA, M. J. L. de. O território: sobre espaço e poder, autonomia e desenvolvimento. In: CASTRO, I. E. de; GOMES, P. C. da C.; CORRÊA, R. L. (Orgs.). Geografia: conceitos e temas. Rio de Janeiro: Bertand Brasil, 2007.

ZALUAR, A. Dilemas da segurança pública do Brasil. In: Desarmamento, segurança pública e cultura da paz. Rio de Janeiro: Fundação Konrad Adenauer, 2005. 